\title{
Female Perspective of Implementing a Failure Learning Orientation
}

\author{
Jenna E. Broderick \\ jenna.broderick@usask.ca| Saskatoon, Saskatchewan, Canada \\ Grant Alexander Wilson \\ gwilson@edwards.usask.ca | Edwards School of Business, University of Saskatchewan, 25 Campus Drive, \\ Saskatoon, Saskatchewan, S7N 5A7, Canada
}

\begin{abstract}
The female perspective of implementing a failure learning orientation was explored through the analysis of interviews with Canadian female executives of technology firms. The results of this study establish several strategies for executives seeking to create a culture that learns from failure. The strategies include reframing failure to mitigate negative emotions, focusing on the root cause of issues, openly discussing failures and strategies, operating proactively, encouraging risk-taking in experimentation, and providing a calming presence.
\end{abstract}

Keywords. Learning from failure; Failure learning orientation; Female executive; Organizational learning; Strategy.

Cite paper as: Broderick, J.E., Wilson, G.A., (2020). Female Perspective of Implementing a Failure Learning Orientation, Journal of Innovation Management, www.open-jim.org, 8(3), 109-123. 


\section{Introduction}

Learning is a fundamental aspect of recovery for organizations faced with failure. Senge (1990) emphasizes the importance of implementing a learning-focused organizational culture. Although not failure focused, Senge (1990) suggests that leading organizations must focus not only on adaptive learning but also generative and creative learning. Considerable research exists on the topic of post-failure learning processes (Cannon and Edmondson, 2005; Cope, 2011; Edmondson, 2011; Shepherd, 2003). The primary focus of these studies has been to provide a foundation for organizations to identify their failures, analyze them from multiple perspectives, and strategize a way forward.

The literature also emphasizes the categorization of failures and the distinction between intelligent and non-intelligent failures (Edmondson, 2011). Intelligent failures are those that result in new knowledge that can be used to enhance competitiveness (Edmondson, 2011). Non-intelligent failures are those that are avoidable or caused by situational complexity (Edmondson, 2011). Existing research is limited with respect to the identification of how successful organizations can develop a culture that is committed to learning from failure, not just after failures occur. Edmondson (2011) addressed the need for a cultural change that encourages experimentation with the possibility of failure. However, Edmondson (2011) does not address how organizations should create a culture that learns from failure. In a study of technology-based start-ups, Wilson (2019) introduced the notion of failure learning orientation (FLO), a novel strategic orientation that conceptualizes firm-level learning from failure. Although it is similar to Rami and Gould's (2016) learning from failure culture, it is more comprehensive. Rami and Gould (2016) suggest three imperatives for learning from failure, including the elimination of error coverups, the encouragement of error communication, and the need for peer and leadership commitment. Wilson's (2019) FLO is more expansive including six essential elements of a culture committed to learning from failure. Specifically, firms that are failure learning-oriented (1) are committed to learning from failure, (2) promote open discussions of failures, (3) think that failing fast helps them learn faster, (4) seek to understand why failures occur as opposed to who was responsible for them, (5) focus on strategies to move forward after failure, and (6) believe that learning from failures is a competitive advantage (Wilson, 2019).

This paper introduced the concept of FLO and it provided empirical evidence that supported its link to firm performance (Wilson, 2019). Until recently, there was a gap in the literature as to how organizations could implement a culture of this kind. Recently, Wilson and Dobni (2020) explored the activities of chief executive officers (CEOs) to determine how a failure learning-oriented culture could be created. Wilson and Dobni's (2020) study offered five strategic imperatives for implementing a failure learning-oriented culture. According to Wilson and Dobni (2020), "failure needs to be positively reframed, the process needs to be supported with resources, everyone must be solution-oriented, incentives and acknowledgment for risk-taking are critical, and failure consequences must be reconsidered or removed" (p. 27). As Wilson and Dobni (2020) suggest, future research should explore the implementation of FLO with more executives and in differing cultural and industry contexts. Incidentally, the literature lacks a female executive perspective related to the creation of an organizational culture that prioritizes learning from failure. As Koellinger et al. (2013) suggest, females may be more afraid of failing than their male counterparts 
and per the call for future research, this study replicates Wilson and Dobni's (2020) study with female executives of technology enterprises in Canada.

\section{Learning from Failure}

\subsection{Cultural Implementation of Learning Organizations}

According to Senge (1990), successful leaders must take on the role of designers, teachers, and stewards. Senge's (1990) work emphasizes a leader's responsibility to foster an environment that is conducive to learning and improving. It is further argued that leaders must support their employees by sharing their vision and asking for feedback. Senge (1990) also addresses the idea that leaders must challenge current cultures that hinder innovation. According to Cameron and Quinn (2011), there are four types of organizational cultures including clan, adhocracy, market, and hierarchy. Clan cultures are internally focused and flexible, adhocracy cultures are externally focused and flexible, market cultures are external focused and controlled, and hierarchy cultures are internally focused and controlled. Adhocracy cultures are congruent with learning organizations, as the environment is dynamic and committed to learning in their efforts to create superior value. As Cameron and Quinn (2011) suggest, it is important for executives to first understand the current culture to make desired changes.

Senge (1990) discusses the need for leaders to examine the big picture of their organization and avoid systematic problem-solving. Being a learning organization is essential to navigating dilemmas strategically, by slowing down and assessing the situation using all the facts and multiple tools. Leaders' preconceived mental models limit innovative ideas. Learning organizations are said to be more agile, nimble, quick to pivot, and predict market trends (Jiménez-Jiménez and Sanz-Valle, 2011). Firm-level learning orientation and organizational learning have been directly and indirectly linked to performance (Calantone et al., 2002; Jain and Moreno, 2015; JiménezJiménez and Sanz-Valle, 2011; Tippins and Sohi, 2003). Learning orientation, described as a firm's commitment to learning, shared vision, open-mindedness, and organizational knowledge sharing resemble many of the ideas introduced by Senge (1990). For a learning-oriented organization to be truly effective, all individuals must be willing to accept the shared vision. Calantone et al. (2002) concluded that learning orientation had a significant impact on both innovativeness and performance. When an organization can implement a culture that is dedicated to learning, they develop a unique competitive advantage. Calantone et al. (2002) suggest that an organization that is committed to learning can fully comprehend not only their products and product development, but also their customers and competitors. As positive as it is for businesses to invest in becoming learning organizations, Cannon and Edmondson (2005) found that few firms understand this and how to implement a culture that supports learning from failure.

\subsection{Post-Failure Learning Processes}

Cannon and Edmondson (2005) proposed that the key to learning from failure is to identify, analyze, and strategize based on organizational failures. Other studies conducted on post-failure 
learning processes also support these sentiments (Pretorius, 2008; Shepherd, 2003; Sitkin, 1992). Effectively learning from failure is dependent on the identification of failures (Cannon and Edmondson, 2005). The identification and categorization of failure are significantly more complex than one may think.

For this reason, Edmondson (2011) developed a spectrum of reasons for failure that range from blameworthy to praiseworthy. According to Edmondson (2011), not all failures are created equal, and failure is not always bad. Edmondson (2011) purports that all failures can be categorized into three categories, the first being preventable, which are regarded as "bad" as they are generally caused by employees failing to follow specific procedures. The second is complexity-related failures, and this is when failures occur due to the nature of the organization, industry, or environment. They are further broken down into severe and small process failures, the former being preventable with proper precautions and the latter being generally unavoidable. Although small failures should not be considered "bad", it is essential to address and correct them (Edmondson, 2011). It is often difficult for organizations to recognize small, everyday failures (Cannon and Edmondson, 2005). Cannon and Edmondson (2005) argue that when organizations do not proactively identify and address small failures, more harmful failures become more difficult to prevent. Lastly, Edmondson (2011) talks about intelligent failures at the frontier. These should be regarded as "good" because they are the result of experimentation that assists the organization with learning, growing, and innovating (Edmondson, 2011).

To further the idea that not all failures are created equally, Shepherd (2003) studied the grief and recovery process of failed businesses. During the identification, it was noted that failure does not have to signify the end of the business entirely. With the appropriate identification of failure origins, executives can move to the analysis and forward-focused strategic planning. For executives, it is often difficult to come to terms with failures and tend to disassociate themselves from them (Cannon and Edmondson, 2005). This type of behavior can have detrimental effects, as employees may be less likely to identify their failures, eliminating potential learning (Cannon and Edmondson, 2005). Although Wilson and Dobni (2020) fill a needed gap in the literature, explaining how male CEOs of U.S. technology enterprises implement a culture that learns from failure, further comparative research is required.

Following the initial identification of a failure, to begin learning from the incident, it must be analyzed. Analyzing a failure can be a complex task that not all executives are capable of initiating. This can be due to their emotional capacity for themselves and others (Cannon and Edmondson, 2005). Learning from failure is difficult due to current organizational and psychological factors that hinder the acceptance of any failures (Cannon and Edmondson, 2005). Executives, as well as other individuals, struggle with admitting fault, which in turn can delay time-sensitive analyses. As previously discussed, it is common that executives do not identify failures properly, and the residual effect on the analysis can be immense.

It is essential to discuss the social systems that inhibit individuals from analyzing, discussing, and learning from failures. Cannon and Edmondson (2005) first look at the negative emotions one may have when analyzing their failures. Shepherd (2003) also discusses the negative emotions (e.g. grief) surrounding business failure. The effect on an individual's self-esteem, self-confidence, and ego can interfere with moving forward and learning from failure (Cannon and Edmondson, 
2005; Shepherd, 2003). Analysis can only be successful when executives are capable of deep reflection, patience, and have a tolerance for uncertainty (Cannon and Edmondson, 2005). This can be challenging for those in decision-making positions. People can subconsciously struggle with analyzing their failures due to psychological biases and errors in human perception (Cannon and Edmondson, 2005). To combat these issues with analyzing failures, formal processes need to be created within the organization that guarantees effective analysis and ultimate learning from failures (Wilson and Dobni, 2020).

Cope (2011) suggests that executives need to learn as much as they can about themselves, their entrepreneurial pursuit, and their business environment. The intricacy of an internal and external analysis of failure may seem daunting. Cope (2011) proposes that recovering from failure is just as much about repairing relationships as it is about handling the financial and emotional burdens. Cope (2011) also adds that speed is a significant factor in the recovery process and extended selfcritique can be difficult. Instead of dwelling on the past, Cope (2011) advises reflecting on positive feedback and focus on strategic maneuvering post-failure. Cope (2011) deviates from previous literature that encourages intelligent failures, as they only modestly increased the likelihood of learning. Instead, Cope (2011) introduced a transformative way of looking at failures that drastically redefined learning from failure. Specifically, Cope (2011) proposed that executives should differentiate themselves rather than refine their current behaviors and activities. Existing literature on the analysis of failure learning is intriguing. However, it still lacks how exactly executives, specifically females, can implement a culture that learns from failure.

\subsection{Cultural Implementation of Learning from Failure}

The major focus of the current literature is primarily on learning strategies after the failure has occurred. Rami and Gould (2016), were the first to offer three "critical factors which support or inhibit the development" of a culture that learns from failure (p. 161). The first factor relates to the dialogue between superiors and subordinates. Rami and Gould (2016) suggest that a culture that supports open communication reduces error cover-up and fosters learning. The second factor that promotes learning from failure is a culture of mutual social support. Rami and Gould (2016) found that "high social support by superiors and colleagues/peers has a favorable impact on error communication" resulting in learning (p. 166). Third, they argue that social backing or cohesion is a requirement for creating a culture that learns from failure. Despite its importance, Rami and Gould's (2016) factors support learning from failure are limited and non-specific.

Wilson's (2019) study comprehensively conceptualized a new strategic orientation that focused on learning from failure. Wilson (2019) also explored its effect, among other strategic orientations, on performance. Wilson (2019) found that alliance orientation and FLO had a direct and positive effect on firm performance whereas market orientation's effect on performance was indirect via FLO. Not only did this study conceptualize a strategic orientation that measured firm-level commitment to learning from failure, but it showed its empirical link to performance.

Building on the works of Wilson (2019), Wilson and Dobni (2020) identified five common strategies to implement a failure learning-oriented culture. The five strategies included (1) commitment to culture change, (2) reframing failure to have positive connotations, (3) discovering 
faster by resource commitments, (4) rewarding risk-taking, and (5) eliminating consequences of failures (Wilson and Dobni, 2020). There is still a need for additional research that explores the implementation of FLO from additional perspectives (e.g. female executives).

Females often struggle to attain senior executive roles and if they do achieve them, they are often faced with great scrutiny (Eagly et al., 1992). Females are stereotyped as a more emotional gender, and the implications of this bias are exemplified by being in a highly visible role (Brescoll, 2016). When conveying emotions of sadness and anger, female executives are often viewed as less effective (Lewis, 2000). In addition to the lack of female representation in leadership, on average, females are more afraid of failure (Koellinger et al., 2013). According to the National Post (2017), less than five percent of Canadian technology CEOs are females. Moreover, females are largely underrepresented on executive teams of Canadian technology companies. Despite the underrepresentation, more women are entering technology-intensive industries, resulting in a growth of representation in all roles including executive management (National Post, 2017).

\section{Research Methodology}

\subsection{Purpose}

The purpose of this study is to further explore how female executives can implement a culture that learns from failure. This study is distinct as it offers strategies to implement a failure learning-oriented culture from the female perspective.

\subsection{Sample}

Eight semi-structured interviews were conducted with female senior executives (e.g. CEOs) of Canadian technology firms. Given there is no sample size requirement for qualitative research, interviews were continued until data saturation was achieved (Richards and Morse, 2012). Per Richards and Morse (2012), data saturation exists when all data categories are rich and replicated. Each female executive was identified from the personal network of the authors and explicitly indicated that they implemented an organization culture that learns from failure. Purposeful sampling was used to recruit interviewees as it allowed for the selection of participants based on the research question (Matheson, 2005). The interviews were conducted in 2020 and sought to stimulate dialogue regarding how the interviewee's implemented an organizational culture that learns from failure.

\subsection{Data Analysis}

The qualitative software NVivo was used to thematically analyze the interview transcripts. According to Braun and Clarke (2006), thematic analysis is widely used and a "foundational method for qualitative analysis" (p. 77). This method of analysis is used to reveal and interpret the themes and patterns within a set of data. The six phases of Braun and Clarke's (2006) thematic analysis method were employed. Phase one of the thematic analysis included familiarization with 
the data by rereading the transcripts and searching intently for meanings. The second phase included generating a set of data codes for all ideas presented within the transcripts. The researchers initially identified 52 codes. In the third phase of the thematic analysis, the researchers collapsed the 52 codes into 35 codes and categorized them based on similarities. Specifically, the codes were grouped to form 10 larger concepts. As per Braun and Clarke's (2006) recommendations, in phase four, the researchers formalized and refined the themes. The initial 10 concepts were refined to six distinct themes related to the implementation of a culture that learns from failure. In the fifth phase, the vetted themes were named and their interrelatedness was established. In the final phase, the researchers discussed in-detail, using quotes, the themes and their meanings.

\section{Results}

Following a thematic analysis of the interview transcripts using the mentioned methodology, six themes were discovered concerning the implementation of learning from failure. The themes offer unique additions and differences to Wilson and Dobni's (2020) findings. The six themes were, (1) reframing failure, (2) uncovering the root cause, (3) encouraging open discussion, (4) operating proactively, (5) stimulating risk-taking in experimentation, and (6) providing a calming presence. The sections below further explain and offer instances of these six themes being emphasized as successful strategies for prioritizing learning from failure.

\subsection{Reframing Failure}

As suggested by Shepherd (2003), there are negative emotions surrounding failure that affect how individuals can move forward and learn from failure. Similar to Wilson and Dobni (2020), female executives also discussed the need to reframe failure, as it has negative connotations. Specifically, all interviewees wanted to deviate from the word. One female executive stated:

"... failure is an interesting word. Is it really failure or is it just really learning? You have tried one path, and maybe it didn't work, so what are you doing to recalculate to go into a different path."

The executives often referred to issues as "missteps" or "opportunities of improvement" rather than failures. Although Shepherd (2003) suggests that failure does not have to indicate the end of a business, all female executives understood failure to only mean the end of their business. As stated by one interviewee:

"I find failure an extremely strong word because if that were the case, we would have been out of business a long time ago."

A collective thought among the executives was to not dwell on the fact that a misstep has occurred, but rather, work toward uncovering the root cause and solution. 


\subsection{Uncovering the Root Cause}

One of the most prominent notions from the conceptualization of FLO was shifting the focus to why failures occur as opposed to those who are responsible for its occurrence (Wilson, 2019). This was reinforced during the interviews with female executives. All interviewees referred to creating environments where employees did not feel intimidated to try new things. Moreover, similar to Wilson and Dobni's (2020) findings, female executives discussed how employees should not be reprimanded for failures. Instead, organizations should work toward discovering the root cause of the problem rather than to point fingers. As previously discussed, the repercussions of redundant, misdirected blame, and punishing can be detrimental (Cannon and Edmondson, 2005). One female executive stated:

"... you can point fingers and blame people, but it really doesn't help. The faster that you move from [the] disaster that happened to what are we doing as a result, the better off you will be."

Among the female executives, there was consensus that focusing on who was to blame was largely time-consuming and unproductive. Therefore, as Wilson and Dobni (2020) found, the goal should be to create an open forum for failure discussions to objectively move forward post-failure.

\subsection{Encouraging Open Discussion}

Open discussion of failures is an integral aspect of FLO (Wilson, 2019; Wilson and Dobni, 2020). The overwhelming consensus from all the female executives was that open discussion among employees and executives was essential to promote FLO. This theme was also congruent with the works of Rami and Gould's (2016) suggesting error communication is essential to learning from failure. Commonly, female executives suggested that in-depth strategic planning including input from every employee was also essential. The encouragement of open discussions was the result of what one female executive specified as a safe culture. The need for a safe culture was congruent with Rami and Gould's (2016) culture of mutual social support. The interviews with female executives also highlighted the necessity for a clear and concise vision. The foundation of open discussion is not advantageous if the strategy is not well-defined. One executive stated that her definition of success was:

"... having a crystal-clear vision. The biggest missteps have been when not everyone /understood] the vision or what the definition of success in that vision [looked] like."

This female executive, along with the others, highlighted the importance of sharing a well-defined vision with employees with the intent of working toward a common goal. This was particularly noteworthy, as it was not mentioned in Wilson and Dobni's (2016) study, offering an additional unique consideration for implementing FLO. These female executives acknowledged their role in implementing strategies related to learning from failure. The intent of open discussion, according to one executive, was:

"[to] remind everyone where we are marching and [show] how we are doing in that journey." By communicating and reminding everyone about the organizational goals, executives were better 
able to assist in problem-solving when failures occurred. The female executives frequently referred to collaborative efforts. A common belief among the female executives was that to implement a culture that prioritizes learning from failure successfully, continuous learning must occur.

\subsection{Operating proactively}

In addition to openly discussing failures with employees, the female executives agreed that frequent checks with employees prevented major failures. Strategizing on how to move forward from failure is one of the fundamental aspects of the FLO (Wilson, 2019). All the executives identified how they needed to have a proactive approach to failure. One executive said:

"If you wait for a month or a quarter or a year check-in, [the issue] becomes a colossal failure if you're not checking in regularly."

As previously mentioned, Cannon and Edmondson (2005) found that extensive failures are difficult to prevent when organizations do not proactively identify and address small failures. The female executives agreed that the advantage of a proactive strategy was that issues can be better managed and addressed with little disruption. Moreover, the ability to be proactive stemmed from the encouragement of risk-taking and the understanding of what did not work.

\subsection{Stimulating Risk-Taking in Experimentation}

Building on the idea of a safe culture is the willingness and encouragement of experimentation. It was evident from the interviews that a crucial aspect of implementing a failure learningoriented culture was to be consistently taking calculated risks. Edmondson (2011) previously acknowledged that experimentation produces "good" failures because they facilitate learning and innovation. One female executive stating that an organization should be actively looking for pain-points:

"... we run an experiment every month where we essentially look for failures and then put more resources and time behind what is working well."

Frequent experimentation does not come without the possibility of failure. The consensus was that relentless experimentation is best accompanied by an assessment of the risks associated with the experiment. This was congruent with Wilson and Dobni's (2020) theme that suggested executives' need to incentivize and acknowledge risk-taking and encourage smart failures that lead to progress. However, female executives acknowledged that the assessments could occasionally be precarious. Referencing a specific ongoing experiment, one executive stated:

"... when you do the risk-reward analysis; we think that the risk [of failure] is worth it because the reward would be monumental for us."

Female executives also noted that another advantage to frequent experimentation was the ability to fail fast and, thus, succeed faster. Failing fast is a core principle of FLO (Wilson, 2019) and is generally acknowledged as essential to learning (Edmondson, 2011). Female executives who encouraged their teams to experiment with the propensity to fail must also have the temperament and emotional capacity to analyze failures when they occur (Cannon and Edmondson, 2005). 
The female executives further supported this notion agreeing that they need to remain calm and refrain from overreacting.

\subsection{Providing a Calming Presence}

During the interviews, female executives made specific comments divulging how to best proceed with managing failures. These descriptions included remaining calm and providing a reassuring presence in the situation. This was perhaps the most unique research finding, as existing research on learning from failure has not made mention of the emotional response to executives in the face of failure. One executive depicted their style by stating:

"For me, as a leader, it is about not overreacting. It is important to be the up-person. Even though you might be peddling underwater pretty hard, as an executive, it is important to stay calm."

To foster an organization's FLO, all executives agreed that employees must feel reassured. One executive identified the key to the organization's success as:

". . providing a steadiness or calmness to the situations that come up. If there is a problem and they come to me, it is going to be handled and taken care of as quickly and reasonably as possible."

All female executives agreed that failing or making mistakes is inevitable. However, how a situation is handled has an impact on what is learned from the experience.

\section{Discussion}

The interviews conducted with eight Canadian female executives revealed six major themes regarding strategies for implementing a failure learning-oriented culture. The first theme suggested that executives disliked the term failure. The words "missteps" or "opportunities for improvement" were used in replacement. This is congruent with Shepherd's (2003) notion that the negative emotions surrounding failure make the process of learning difficult. Wilson and Dobni (2020) also found a similar result suggesting CEOs regarded failures as discoveries.

The second theme emphasized how uncovering the root cause of problems is considerably more important than blame. Wilson and Dobni (2020) highlighted the removal of negative consequences to incentivize risk-taking. In varying ways, all the female executives spoke about creating a safe culture for employees to experiment and fail as needed. This was congruent with Rami and Gould's (2016) culture of mutual support and the idea the repercussions for misdirected blame can be detrimental (Cannon and Edmondson, 2005).

The third theme reiterated one of the core concepts of FLO, openly discussing strategies, and failure (Wilson, 2019). The female executives all referred to how their organization provided visible and inclusive in-depth strategic planning. The female executives also recognized their role in facilitating open discussions. Implementing a culture that prioritizes learning from failure is only possible when all employees are encouraged to participate. The need for executives to 
explicitly share a well-defined vision that includes learning from failure was a unique element of this theme, furthering the understanding of how to implement a failure learning-oriented culture.

The fourth theme highlighted the importance of being proactive rather than reactive. Cannon and Edmondson (2005) suggested that major failures are difficult to prevent when small failures are not identified and addressed. Female executives' responses were distinctly fitting, as they all referenced the importance of frequent checks with employees. Failures were perceived as more manageable when they were identified promptly.

The fifth theme was related to prioritizing risk-taking in experimentation. Edmondson (2011) suggested that experimentation facilitates innovation and learning through smart failures. Female executives described the different ways their organizations provided frequent opportunities for experimentation and were able to put resources behind them. This was similar to Wilson and Dobni's (2020) findings that suggested executives have to be fully committed to the discovery process, thereby pledging significant financial resources and human capital.

Interestingly, all female executives described extensive risk assessments. This is somewhat related to the Koellinger et al.'s (2013) proposition that females are more afraid of failing and are subject to disproportionate scrutiny (Brescoll, 2016; Eagly et al., 1992). Female executives also stated that their competitive advantage was related to failing fast, a foundational aspect of FLO (Wilson, 2019).

The sixth and final theme provided a unique contribution to the understanding of implementing a failure learning-oriented culture, as it was not identified in Wilson and Dobni's (2020) study. All female executives referenced how it was their role to remain calm and not overreact to failures. All female executives agreed that failure is inevitable and learning from the experience is dependent on how the situation is handled.

\section{Conclusions}

Until recently, literature was primarily concentrated on post-failure learning. Although Rami and Gould (2016) proposed strategies to create an organizational culture that learns from failure, they were somewhat generic and limited. Wilson and Dobni's (2020) study explicated several strategies to implement a culture that learns from failure, but it was also limited to male CEOs of U.S. technology companies. This study replicates Wilson and Dobni's (2020) research in a new country among female executives. Although there were several commonalities among the findings, key differences were found. This study suggests six implementation strategies including (1) reframing failure, (2) uncovering the root cause, (3) encouraging open discussion, (4) operating proactively, (5) stimulating risk-taking in experimentation, and (6) providing a calming presence. This study differs in that it finds, a calming presence and explicitly communicating a learning-focused vision is key to implementing FLO. This study is important as it articulates strategies used by Canadian female executives to successfully implement FLO in their organizations. Managerial implications of implementing FLO are significant, as it has been empirically linked to performance among technology-based enterprises (Wilson, 2019). There- 
fore, it is particularly relevant to executives looking to create a culture that promotes learning, fosters innovation, and enhances performance.

\section{Limitations}

This study was limited to the perspectives of eight female executives of Canadian technology enterprises. However, there is no sample size requirement for qualitative research, only a requirement that data saturation is achieved (Richard and Morse, 2012). Given data saturation was achieved and the few female executives among Canadian technology firms (National Post, 2017), eight respondents were deemed appropriate. Although female executives were identified from the personal networks of the authors, such recruitment methodologies are standard practice in qualitative research (Matheson, 2005), especially if the research question is highly specific (e.g. implementing FLO). Although the identification specifications were deliberate, additional female executives in Canada and from other countries may have provided additional insight into the implementation of a culture that prioritizes learning from failure. The study was limited to technology-intensive firms and the exploration of other exploration of industries may also have yielded further insights.

\section{Future Research}

Future research on the conceptualization of female executives implementing failure learning orientation could explore female executives in varying industries, countries, and other social contexts.

\section{Conflicts of Interest}

The authors declare they have no conflicts of interest.

\section{References}

Ayres, L. (2008). Semi-structured interview. In L. M. Given (Ed.), The SAGE encyclopedia of qualitative research methods (pp. 811-812). Thousand Oaks, CA: Sage Publications, Inc.

Baumard, P., \& Starbuck, W. H. (2005). Learning from failures: Why it may not happen. Long Range Planning, 38(3), 281-298.

Braun, V., \& Clarke, V. (2006). Using thematic analysis in psychology. Qualitative Research in Psychology, 3(2), 77-101.

Brescoll, V. (2016). Leading with their hearts? How gender stereotypes of emotion lead to biased evaluations of female leaders. The Leadership Quarterly, $27(3), 415-428$. 
Calantone, R. J., Cavusgil, S. T., \& Zhao, Y. (2002). Learning orientation, firm innovation capability, and firm performance. Industrial Marketing Management, 31 (6), 515-524.

Cameron, K. S., \& Quinn, R. E. (2011). Diagnosing and changing organizational culture: Based on the competing values framework. John Wiley \& Sons.

Cannon, M., \& Edmondson, A. (2005). Failing to learn and learning to fail (intelligently). Long Range Planning, 38(3), 299-319.

Cardon, M. S., Stevens, C. E., \& Potter, D. R. (2011). Misfortunes or mistakes?: Cultural sensemaking of entrepreneurial failure. Journal of Business Venturing, 26(1), 79-92.

Cope, J. (2011). Entrepreneurial learning from failure: An interpretative phenomenological analysis. Journal of Business Venturing, 26(6), 604-623.

Eagly, A. H., Makhijani, M. G., \& Klonsky, B. G. (1992). Gender and the evaluation of leaders: A meta-analysis. Psychological Bulletin, 111(1), 3.

Edmondson, A. C. (2011). Strategies for learning from failure. Harvard Business Review, 89(4), $48-55$.

Jain, A. K., \& Moreno, A. (2015). Organizational learning, knowledge management practices and firm's performance. The Learning Organization, 22(1), 14-39.

Jiménez-Jiménez, D., \& Sanz-Valle, R. (2011). Innovation, organizational learning, and performance. Journal of Business Research, 64(4), 408-417.

Koellinger, P., Minniti, M., \& Schade, C. (2013). Gender differences in entrepreneurial propensity* gender differences in entrepreneurial propensity. Oxford Bulletin of Economics 85 Statistics, $75(2), 213-234$.

Matheson, S. (2005). Encyclopedia of Evaluation. Thousand Oaks, CA: Sage Publications, Inc.

National Post. (2017). Only 5\% of Canadian tech companies have female chief executives: report. Accessed August $1^{\text {st }}$ 2020. https://nationalpost.com/pmn/news-pmn/canada-news-pmn/ only-5-of-canadian-tech-companies-have-female-chief-executives-report

Pretorius, M. (2008). Critical variables of business failure: A review and classification framework. South African Journal of Economic and Management Sciences, 11(4), 408-430.

Rami, U., \& Gould, C. (2016). From a "culture of blame" to an encouraged "learning from failure culture". Business Perspectives and Research, 4(2), 161-168.

Richards, L., \& Morse, J. M. (2012). Readme first for a user's guide to qualitative methods. Sage Publications, Inc.

Senge, P. (1990). The leader's new work: building learning organizations. Sloan Management Review, 32(1), 7.

Shepherd, D. A. (2003). Learning from business failure: Propositions of grief recovery for the self-employed. Academy of Management Review, 28(2), 318-328. 
Sitkin, S. (1990). Learning through failure: the strategy of small losses, Research in Organizational Behavior, 14, 231-266.

Slater, S., \& Narver, J. (1994). Market orientation, customer value, and superior performance. Business Horizons, 37(2), 22-28.

Tippins, M. J., \& Sohi, R. S. (2003). IT competency and firm performance: is organizational learning a missing link? Strategic Management Journal, 24(8), 745-761.

Wilson, G. A. \& Dobni, C. B. (2020), Implementing a failure learning orientation. International Technology Management Review, 9(1), 27-33.

Wilson, G. A. (2019). Failure learning orientation and technology start-up performance. Journal of High Technology Management Research, 30(2), 1-9. 


\section{Biographies}

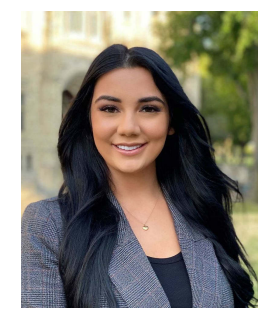

future.

Jenna E. Broderick. Originally from Regina, Saskatchewan, Jenna Broderick is a 2020 B.Comm. (Hons.) student majoring in marketing at the University of Saskatchewan in Saskatoon, Saskatchewan. Early in her university career, Jenna took a keen interest in research related to organizational learning and woman in business leadership. Prior to her final year of studies, she was awarded a Disney Canadian internship spending a semester working in Florida at Walt Disney World while attending Disney University programs. Upon completion of her studies, she has secured a role as an online marketing specialist for Cadillac of Beverly Hills, California. Jenna looks forward to continuing her education and research in the near

CRediT Statement: Formal analysis, investigation, writing - original draft.

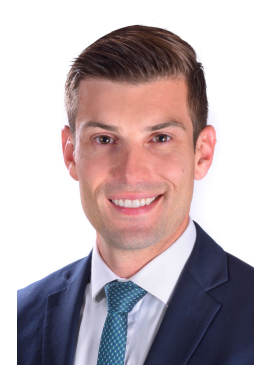

Grant Alexander Wilson. Grant Alexander Wilson is a Faculty Member in the Department of Management and Marketing at Edwards School of Business. Dr. Wilson earned a B.Comm. (Hons.) in marketing, M.Sc., and Ph.D. from the University of Saskatchewan, Saskatoon, Saskatchewan, Canada. Dr. Wilson teaches strategic management, entrepreneurship, technology commercialization, and marketing courses. His current research interests include strategic entrepreneurship, marketing, consumer economics, and organizational learning.

CRediT Statement: Conceptualization, methodology, formal analysis, investigation, writing original draft, writing-review and editing, supervision. 